\title{
Biophysical evaluation of cells on nanotubular surfaces: the effects of atomic ordering and chemistry
}

This article was published in the following Dove Press journal:

International Journal of Nanomedicine

12 August 2014

Number of times this article has been viewed

\author{
Tolou Shokuhfar ${ }^{1-3}$ \\ Azhang Hamlekhan' \\ Jen-Yung Chang' \\ Chang Kyoung Choi' \\ Cortino Sukotjo 4 \\ Craig Friedrich' \\ 'Department of Mechanical \\ Engineering-Engineering Mechanics, \\ Multi Scale Technologies Institute, \\ Michigan Technological University, \\ Houghton, MI, ${ }^{2}$ Department of \\ Physics, University of Illinois at \\ Chicago, Chicago, IL, ${ }^{3}$ Department of \\ Mechanical and Industrial Engineering, \\ University of Illinois at Chicago, \\ IL, ${ }^{4}$ Department of Restorative \\ Dentistry, Comprehensive Dental \\ Implant Center, University of Illinois \\ at Chicago, College of Dentistry, \\ Chicago, IL, USA
}

\begin{abstract}
After the implantation of a biomaterial in the body, the first interaction occurs between the cells in contact with the biomaterial surface. Therefore, evaluating the cell-substrate interface is crucial for designing a successful implant. In this study, the interaction of MC3T3 osteoblasts was studied on commercially pure and alloy (Ti6A14V) Ti surfaces treated with amorphous and crystalline titanium dioxide nanotubes. The results indicated that the presence of nanotubes increased the density of osteoblast cells in comparison to bare surfaces (no nanotubes). More importantly, our finding shows that the chemistry of the substrate affects the cell density rather than the morphology of the cells. A novel approach based on the focused ion beam technique was used to investigate the biophysical cell-substrate interaction. The analysis revealed that portions of the cells migrated inside the crystalline nanotubes. This observation was correlated with the super hydrophilic properties of the crystalline nanotubes.
\end{abstract}

Keywords: nanotubes, osteoblasts, titanium dioxide

\section{Background}

As a biomaterial is exposed to in vitro condition or in vivo physiologic environment, proteins that are present in the cell culture media or fluids of the body adsorb to its surface in less than 1 second. Then, the functional groups (ligands) of the adsorbed protein bond with cell surface receptors (integrins). ${ }^{1}$ Particularly, adsorption of vitronectin and fibronectin on the surface, results in formation of an intermediate layer that enhances cell adhesion. ${ }^{2,3}$ A hydrophilic surface shows greater protein adsorption than a hydrophobic surface ${ }^{4}$ which leads to an increase of desirable cellular behavior compared with a hydrophobic surface. ${ }^{5-8}$ The presence of nanoscale features on the surface of implants can enhance the growth and attachment (measured as cell density) of osteoblast bone-forming cells. ${ }^{9}{ }^{10}$ Such enhancement is due to an increase of surface area that provides more area for cell-substrate interaction, more surface energy, more protein adsorption, integrin clustering, and as a result, higher cell adhesion. ${ }^{11,12}$ Since nanometer features can mimic the natural environment to which cells are adapted, ${ }^{13}$ various surface modifications such as sandblasting, coatings, and plasma spraying have been introduced to enhance the biomimicry environment. However, commonly used ceramic coatings have undesirable mechanical properties such as cracking and delamination from the metal substrate. For instance, in titanium (Ti) and hydroxyapatite (HA) plasma spraying, the resulting coating is not the same material as the bulk, due to vaporization, condensation, and substrate temperature variations during high temperature deposition. As a result, there will be residual stress in the coating/substrate
Correspondence: Tolou Shokuhfar Department of Mechanical EngineeringEngineering Mechanics, Multi Scale Technologies Institute, Michigan Technological University, 8I5 RL Smith Building, I 400 Townsend Drive, Houghton, MI 4993I, USA

Tel + I 9063707657

Fax + I 9064872822

Email tshokuhf@mtu.edu 
interface due to expansion coefficient mismatch which leads to cracking and breakdown of the coating. ${ }^{14}$

Hence, development of novel surface modifications with more robust and flexible structures containing nano features will be highly promising for better osseointegration, cell-implant interaction, and implant life cycle. $\mathrm{TiO}_{2}$ nanotubes that cover the surface of Ti implants, and which are fabricated from the bulk material instead of as a coating, offer this flexibility and can relevantly mimic the natural environment of the bone-forming cells. Considering that bone cells in the human body interact with fluid that flows around them in interstitial spaces, ${ }^{15,16}$ the presence of space between tubes is beneficial for transport of waste and nutrients, and therefore cell metabolism. ${ }^{17}$ Since these electrochemically etched nanotubes are from the bulk, there is no interface, leading to much better design and analysis. The electrochemical etching process is performed in ambient temperature, leaving no residual stress due to heating. ${ }^{18,19}$

The effect of nanotubes' wettability, diameter, crystallinity, and alloying elements has been investigated in several studies. ${ }^{20-24}$ Wettability is sharply increased after anodization of flat (without nanotube) Ti, which enhances protein adsorption from body fluids in contact with implant surface and consequently enhances cell adhesion. ${ }^{25-27}$ Popat et al's ${ }^{28}$ results indicated that in comparison to flat Ti surfaces, nanotubular surfaces provided higher cell adhesion, alkaline phosphatase activity, and extracellular matrix (ECM) production as well as enhanced calcium $(\mathrm{Ca})$ and phosphorus $(\mathrm{P})$. In addition, they investigated the biocompatibility of $\mathrm{TiO}_{2}$ nanotubes by implanting disks with nanotubular titania surfaces in rats. Their results showed no inflammatory response or fibrous tissue formation in the tissues surrounding the Ti implant due to the presence of $\mathrm{TiO}_{2}$ nanotubes.

Bjursten et $\mathrm{al}^{29}$ showed that $\mathrm{TiO}_{2}$ nanotube surfaces have nine-fold higher bone-implant interlock compared with sandblasted surfaces. Their histological evaluation showed enhanced bone-implant contact area and increased $\mathrm{Ca}-\mathrm{P}$ levels on $\mathrm{TiO}_{2}$ nanotube surfaces. Hazan et $\mathrm{al}^{30}$ evaluated the effect of titania surface topography on fibroblast behavior. They compared three different surface structures including nanotubes, thin films, and foams of $\mathrm{TiO}_{2}$ and concluded that $\mathrm{TiO}_{2}$ nanotubes showed the best properties for higher cell density. Yao et $\mathrm{al}^{13}$ compared three different surface structures (smooth, nanoparticulate, and nanotubular) and observed that the $\mathrm{Ca}$ deposition by osteoblasts was highest on surfaces with $\mathrm{TiO}_{2}$ nanotubular features. They explained that this finding is based on the fact that the nanotubes provide more surface area and reactive sites for fibronectin protein adsorption which mediates osteoblast adhesion.
Diameter of the nanotubes drastically affects cellular response $^{31,32}$ since it defines the position of transmembrane integrins of attached cells. Integrins transmit the force to actin filaments and cause cytoskeletal tension and consequently cell morphology and signaling is affected. ${ }^{33}$ Reports on the effect of nanotube diameter on cell growth and adhesion are often contrasting. Park et $\mathrm{al}^{34}$ reported the optimized nanotube diameter to be $15 \mathrm{~nm}$ for adhesion of mesenchymal stem cells (MSC) while $\mathrm{Oh}$ et $\mathrm{al}^{35}$ and Brammer et $\mathrm{al}^{17}$ reported that $100 \mathrm{~nm}$ diameter nanotubes provide the highest MC3T3-E1 mouse osteoblast cell density. Oh et $\mathrm{al}^{36}$ also reported that the $100 \mathrm{~nm}$ tube diameter resulted in extremely elongated human MSCs, guiding them to differentiate into specific osteoblast cells. Bauer et $\mathrm{al}^{32}$ investigated the effect of change in dimension and constructive material on MSCs' response attachment and proliferation. They concluded that change in diameter is more effective on cell response compared to change in surface chemistry and length.

The present investigation focuses on the effects of substrate chemistry and atomic ordering on the cell growth and attachment on commercially pure (cp)-Ti and alloy-Ti surfaces with and without nanotubes. MC3T3 osteoblast cells were cultured on the substrates and their growth was characterized by optical microscopy, scanning electron microscopy (SEM), and focused ion beam (FIB) milling and imaging. This is the first study that utilizes the FIB technique to investigate the biophysical behavior of cells on nano textured surfaces such as $\mathrm{TiO}_{2}$ nanotubes. In particular, the architecture of the cell/substrate interface was visualized by SEM and FIB to obtain better insight into the morphological and functional features of interfacial osteoblast cell attachment.

\section{Methods}

The substrates for cell growth were $2 \times 3 \mathrm{~cm}$ flat sheets with thickness of $0.25 \mathrm{~mm}$. Polishing was performed with $0.06 \mathrm{~mm}$ colloidal $\mathrm{SiO}_{2}$. Prior to nanotube formation through anodization etching, the polished substrates were sequentially sonicated in acetone, isopropyl alcohol, and methanol, then rinsed with deionized water, and dried in an $\mathrm{N}_{2}$ stream. The electrolyte was 0.2 weight (wt) \% solution of $\mathrm{NH}_{4} \mathrm{~F}$ in 49 $\mathrm{mL}$ ethylene glycol and $1 \mathrm{~mL}$ deionized water. A constant $60 \mathrm{~V} \mathrm{DC}$ was used for all experiments. After anodization, the samples were rinsed with deionized water and dried in an $\mathrm{N}_{2}$ stream. The experimental setup consisted of a two-electrode arrangement, with copper $(\mathrm{Cu})$ mesh as the counter electrode during different sets of anodization. The spacing between 
the substrates and the counter electrode was approximately $25 \mathrm{~mm}$. The anodization was carried out at room temperature. Post-anodization annealing treatment was conducted using a rapid thermal annealer. A heating $/$ cooling rate of $308^{\circ} \mathrm{C} / \mathrm{min}$ was used, and the substrates were annealed in air at $450^{\circ} \mathrm{C}$ for 3 hours.

To investigate cell density of MC3T3-E1 mouse osteoblasts (CRL-2593, subclone 4, ATCC, Manassas, VA, USA), ${ }^{37}$ each $1 \mathrm{~mL}$ vial of purchased cell was mixed with $10 \mathrm{~mL}$ of alpha Minimum Essential Medium ( $\alpha$-MEM; Invitrogen, USA), 10 vol \% fetal bovine serum (FBS; Invitrogen), and 1 vol \% penicillin-streptomycin (PS; Invitrogen). The cell suspension was incubated at $37^{\circ} \mathrm{C}$ and $5 \mathrm{vol}$ $\% \mathrm{CO}_{2}$ environment until saturation point of approximately 3,000 cells $/ \mathrm{mm}^{2}$ was reached after 72 hours of incubation. Confluent cells were seeded onto the substrates of interest, placed on a 30 -well polystyrene plate and stored in a $37^{\circ} \mathrm{C}$ $\mathrm{CO}_{2}$ incubator for 24,48 , and 72 hours to observe the cell morphology and count the number of cells attached as a function of incubation time.

Field emission scanning electron microscopy (FE-SEM) Hitachi S-4700 was used for surface characterization of the substrates. The length of the nanotubes was determined from cross-section images. Moreover, FE-SEM was used to image the adhered cells. Using energy dispersive spectroscopy (EDS) detector of the FE-SEM, chemical composition data were collected before and after cell culture to investigate the composition of individual nanotubes, confirm alloy nanotube composition characteristics of $\mathrm{Ti}, \mathrm{Al}$, and $\mathrm{V}$, and to detect $\mathrm{Ca}$ and $\mathrm{P}$ deposition after cell adhesion. Extensive care was taken for the preparation of samples for the EDS analysis. The samples were washed several times to eliminate any entrapped media.

After evaluating the cell density and adhesion on $\mathrm{TiO}_{2}$ nanotubes, the cell count experiments were conducted. In order to count the attached cells, samples were rinsed with phosphate buffered saline (PBS), fixed, rinsed again and immediately imaged. Only the attached cells were counted toward the cell density. The high-resolution imaging gave the capability of distinguishing between non-flat and well-spread flat cells and the rinsing followed by rapid fixation removed the non-adherent cells, resulting in a more accurate cell count assay. Five random fields were counted per substrate and all experiments were run in triplicate, repeated at least three times. The mean numbers of total attached cells were calculated from the total cell number counted from five random square areas $\left(1.0 \times 1.0 \mathrm{~mm}^{2}\right)$ of each of the 18 different substrates. The mean numbers of attached cells on the surfaces of the control and nanotube covered samples were compared for 24,48 , and 72 hours of incubation.

For the FIB investigations, the cells were fixed on the nanotube substrates. Substrates with fixed cells were inserted into the specimen chamber of a Hitachi SA-2000 FIB. The rough milling conditions to open a trench in the cell, used ion currents of 5 to $7 \mathrm{nA}$ at $30 \mathrm{kV}$. Lower beam currents of 100 to $670 \mathrm{pA}$ were used to polish the cross section. Beam dwell time for milling was $3 \mu \mathrm{s}$.

\section{Results}

Samples of cp-Ti and Ti6Al4V were used to investigate the effect of nanotubes on adhesion and cell density of osteoblasts due to their biocompatibility and preferred mechanical and biological properties. ${ }^{38-40}$

In order to investigate the biphasic nature of nanotubes, the samples were etched for 30 seconds in $0.5 \% \mathrm{HF}$ (Figure 1). At the initial stage of anodization of cp-Ti samples, a uniform porous structure was formed (Figure 1A-B), which eventually led to the formation of nanotubes (Figure 1C). Figure 1G-L shows the nanotubes after being carefully peeled off from the substrate using a diamond knife to observe their bottom and top morphologies. These images indicate a non-collapsed nanotube structure after anodization duration of 4 hours. No significant morphological difference can be seen between amorphous nanotubes (Figures $1 \mathrm{H}$ and $\mathrm{K}$ ) and crystalline nanotubes (Figures 1I and L).

In order to confirm the presence of atomic ordering in annealed nanotubes, transmission electron microscopy (TEM) and X-ray diffraction (XRD) was utilized (Figure 2). Figure 2A shows a bright field TEM image of amorphous nanotubes. The fuzzy diffraction pattern with no obvious spots of rings (the inset in Figure 2A) indicates lack of crystallinity. High resolution TEM imaging (Figure 2B) confirms the absence of atomic ordering at nanoscale. Similar TEM imaging for annealed nanotubes (Figure 2C and D) shows the presence of diffraction spots and atomic ordering at nanoscale which indicates formation of crystalline structures. The XRD data collected from amorphous and crystalline nanotubes (Figure 2E) indicate that the crystalline nanotubes have an anatase phase. As expected, no obvious peak was observed for amorphous nanotubes. Since the TEM investigation of nanotubes grown on alloy-Ti and cp-Ti did not show any significant difference, the TEM images shown in Figure 2 are applicable for both.

Figure 3A-F shows SEM images of osteoblast cells after 72 hours of incubation on prepared substrates. Figure $3 \mathrm{G}$ 

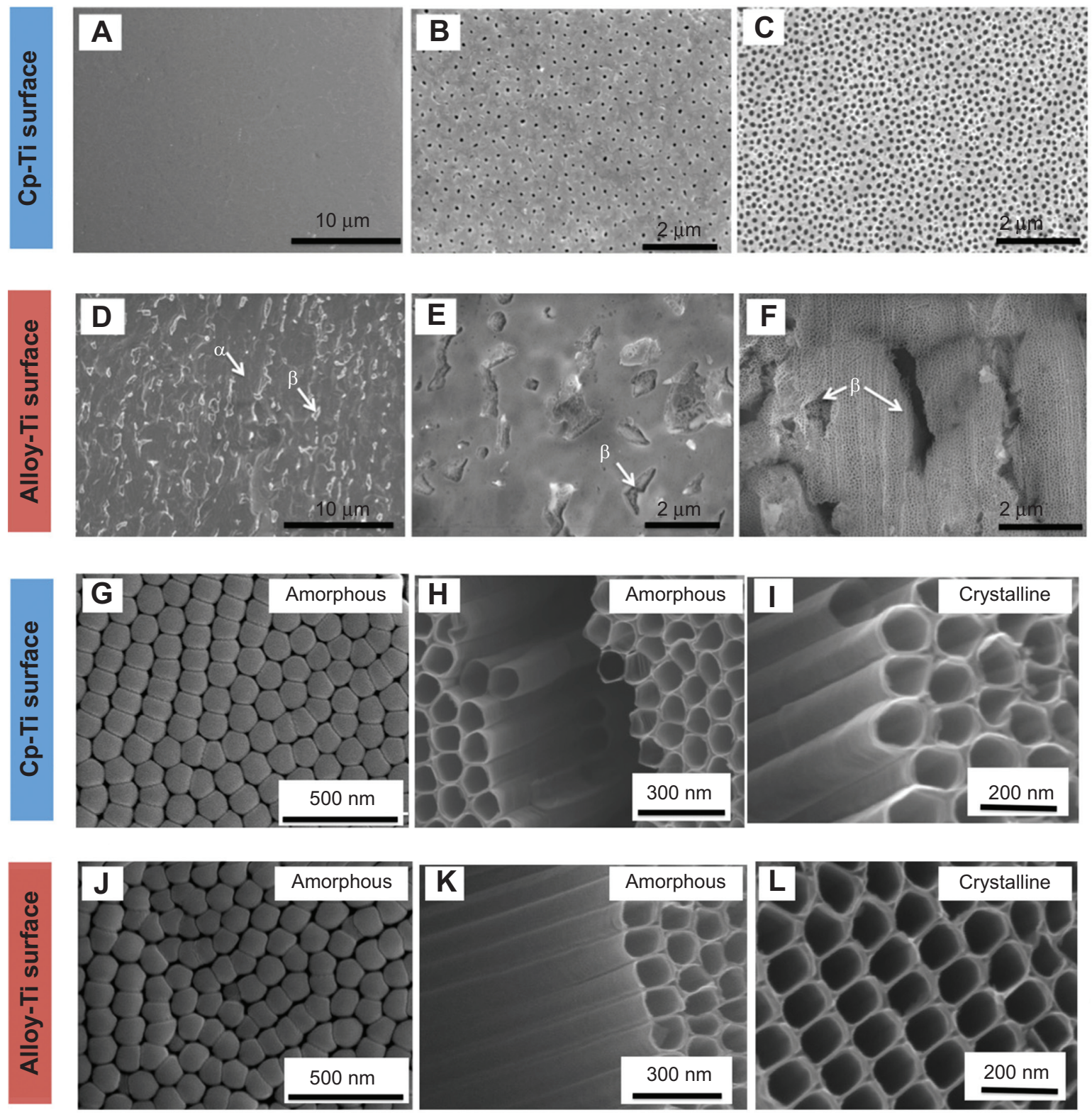

Figure I The scanning electron microscopy (SEM) images show surface morphology on (A-C) cP-Ti and (D-F) alloy-Ti surfaces where (A and $\mathbf{D})$ represent the surface structure before anodization, (B and $\mathbf{E}$ ) initial stage of anodization and (C and $\mathbf{F}$ ) the formation of uniform porous nanotubes. (D-E) Show the presence of two different phases of $\alpha$ and $\beta$. The $\alpha$ phases appear as dark and the $\beta$ phases are bright. As the anodization progresses (F) the $\beta$ phases dissolve leaving behind dark areas indicated by arrows. SEM images of peeled off nanotubes are shown for $(\mathbf{G}-\mathbf{I})$ cp-Ti and $(\mathbf{J}-\mathbf{L})$ alloy-Ti where $(\mathbf{G}$ and $\mathbf{J})$ represent the bottom and $(\mathbf{H}$ and $\mathbf{K})$ top views of amorphous nanotubes and ( $\mathbf{I}$ and $\mathbf{L}$ ) the crystalline nanotubes.

shows a quantitative comparison on the effects of nanotube crystallinity and chemistry on cell density as a function of incubation times (24, 48, and 72 hours).

\section{Revealing the cell-nanotube interfaces}

Following our observation that the crystallinity of the nanotubes is effective on the cell spreading, the efforts in this task were focused on better understanding the interaction of cells with amorphous and crystalline nanotubes. The filopodia extension and anchorage to the nanotubes is clear from
Figure 4, where it shows the interaction of MC3T3 osteoblast cells with $\mathrm{TiO}_{2}$ nanotubes. A single cell sitting on the bed of cp-amorphous $\mathrm{TiO}_{2}$ nanotubes is shown in Figure 4A. An area close to cell filopodia in Figure 4A was selected and enlarged to obtain Figure 4B. As can be seen, the filopodia is adhered to the nanotubes. Figure $4 \mathrm{C}$ clearly shows the opening of the nanotubes and Figure 4D shows that filopodia is "grabbing" the nanotubes as anchors for high attachment. It is interesting to note that the nanotubes remained unfilled. These observations are represented as a schematic in Figure 4E where cell 

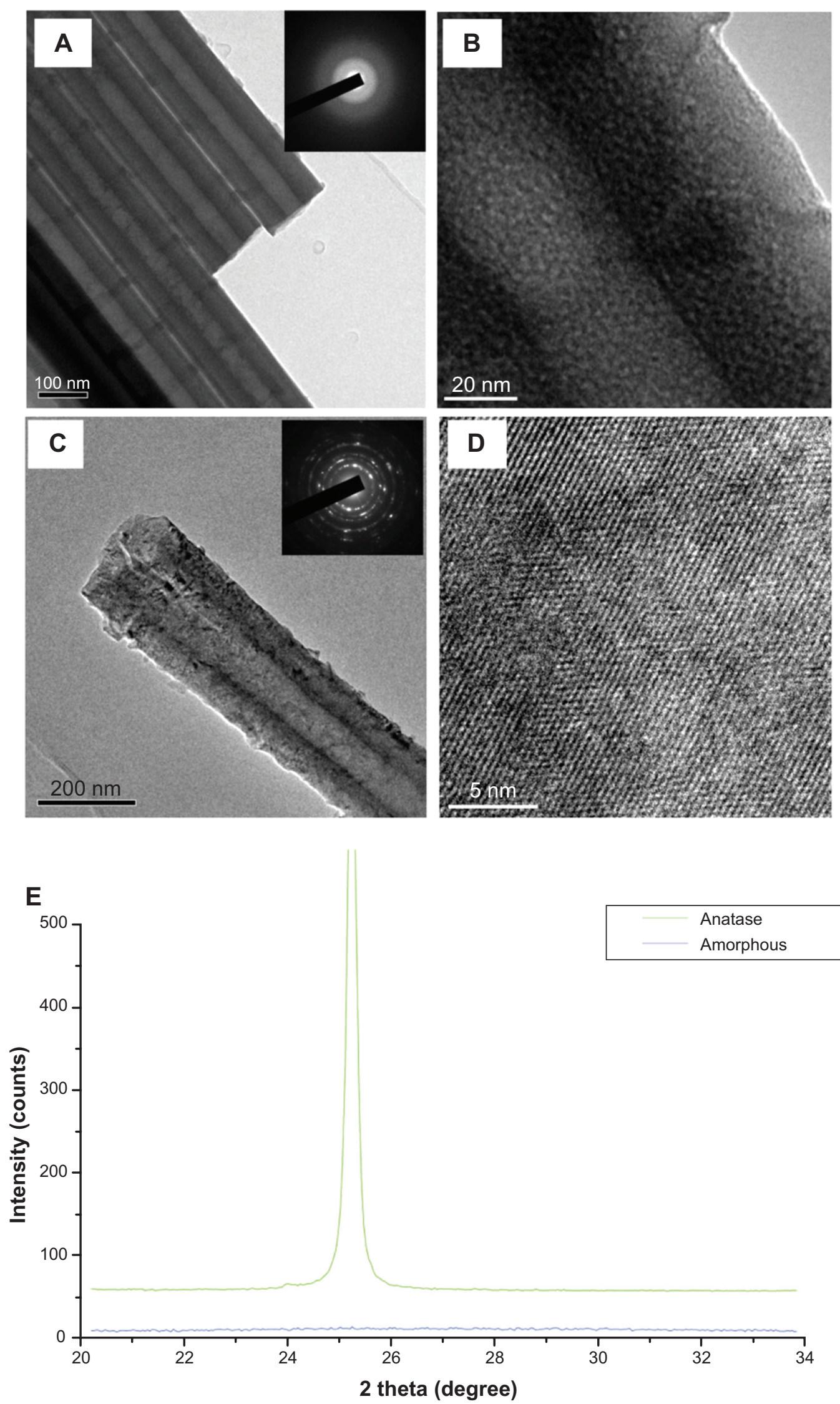

Figure 2 Transmission electron microscopy (TEM) images of (A-B) amorphous and (C-D) crystalline nanotubes are shown. (A and $\mathbf{C})$ Show bright field TEM images of nanotubes. The insets are the corresponding diffraction patterns indicating $(\mathbf{A})$ lack of crystallinity and $(\mathbf{C})$ presence of crystalline structure. (B and $\mathbf{D})$ Show high resolution TEM imaging that confirms atomic ordering at nanoscale. (E) X-ray diffraction data collected from amorphous and crystalline nanotubes. The crystalline nanotubes were identified as anatase phase. 

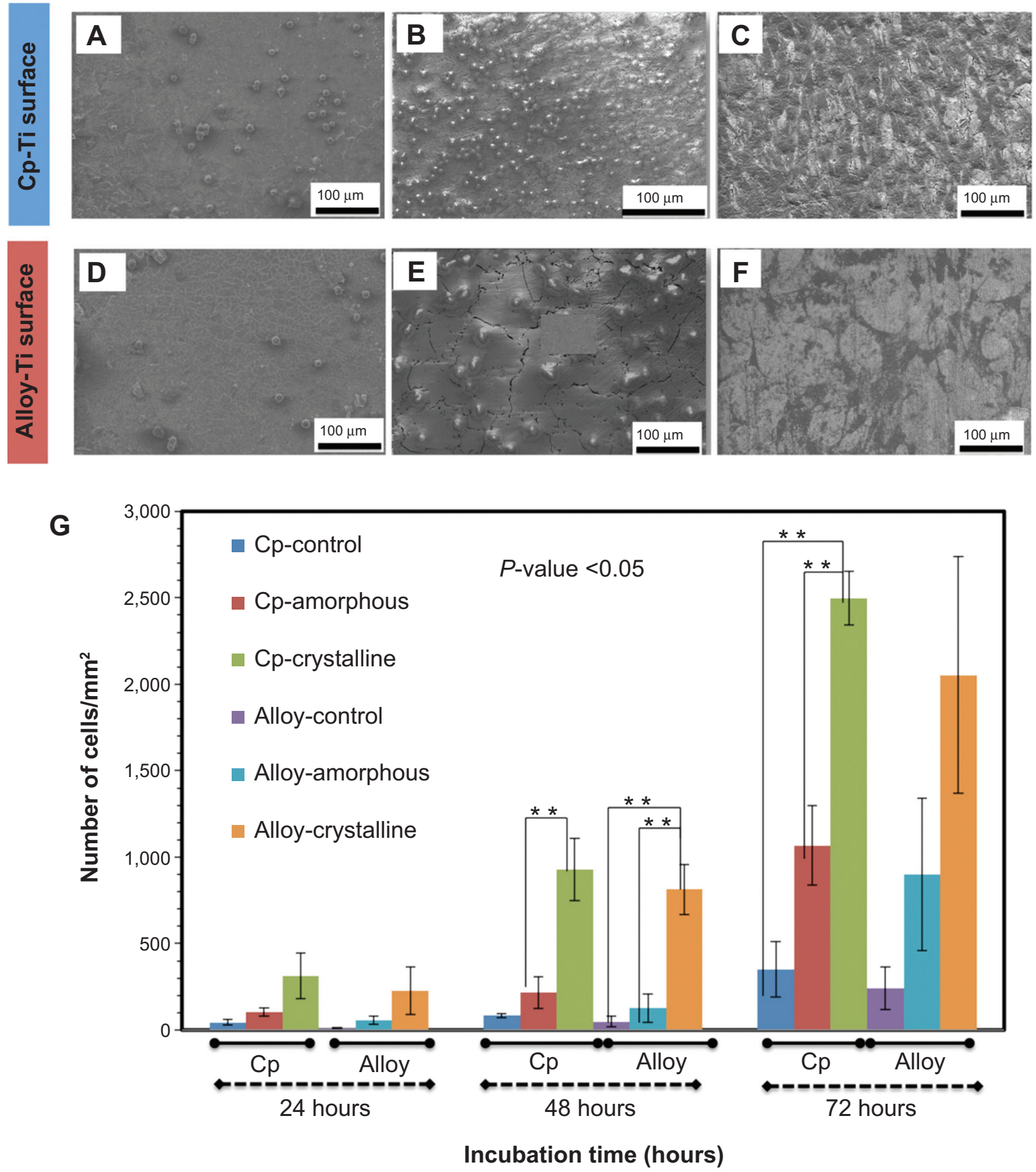

Figure 3 Scanning electron microscopy (SEM) images of osteoblast cells after 72 hours of incubation on (A-C) cP-Ti and (D-F) alloy-Ti where (A and D) represent control (no nanotubes), (B and $\mathbf{E}$ ) amorphous nanotubes and (C and $\mathbf{F}$ ) crystalline nanotubes. (G) Density of adhered MC3T3 osteoblast cells as a function of incubation times $(24,48$, and 72 hours). The symbol **means that the $P$-value is less than 0.05 .

layers are shown to grow on the surface, however, little filling inside the nanotubes can be seen.

The interaction of osteoblast cells with crystalline nanotubes is documented in Figure 4F-J. Figure 4F shows a single cell on the surface of cp-crystalline $\mathrm{TiO}_{2}$ nanotubes. The enlarged image of the dotted box in Figure 4F is shown in Figure 4G. As can be seen in this image, the cell has a much more spread out morphology compared to Figures $4 \mathrm{~A}$ and $\mathrm{B}$. The well spreading is even more obvious from
Figure $4 \mathrm{H}$ which shows that filopodia of the cells enters inside the nanotubes and uses them as anchoring site to enhance spreading and attachment. Figure 4I shows that filopodia has penetrated and grown inside the opening of the nanotubes and thus the opening of the nanotubes no longer remains open. These observations are summarized in the schematic Figure 4J where it is shown that the cell layer grows inside the opening of the nanotubes resulting in their spreading and better attachment to the surface. 


\section{cp-amorphous $\mathrm{TiO}_{2}$ nanotubes}
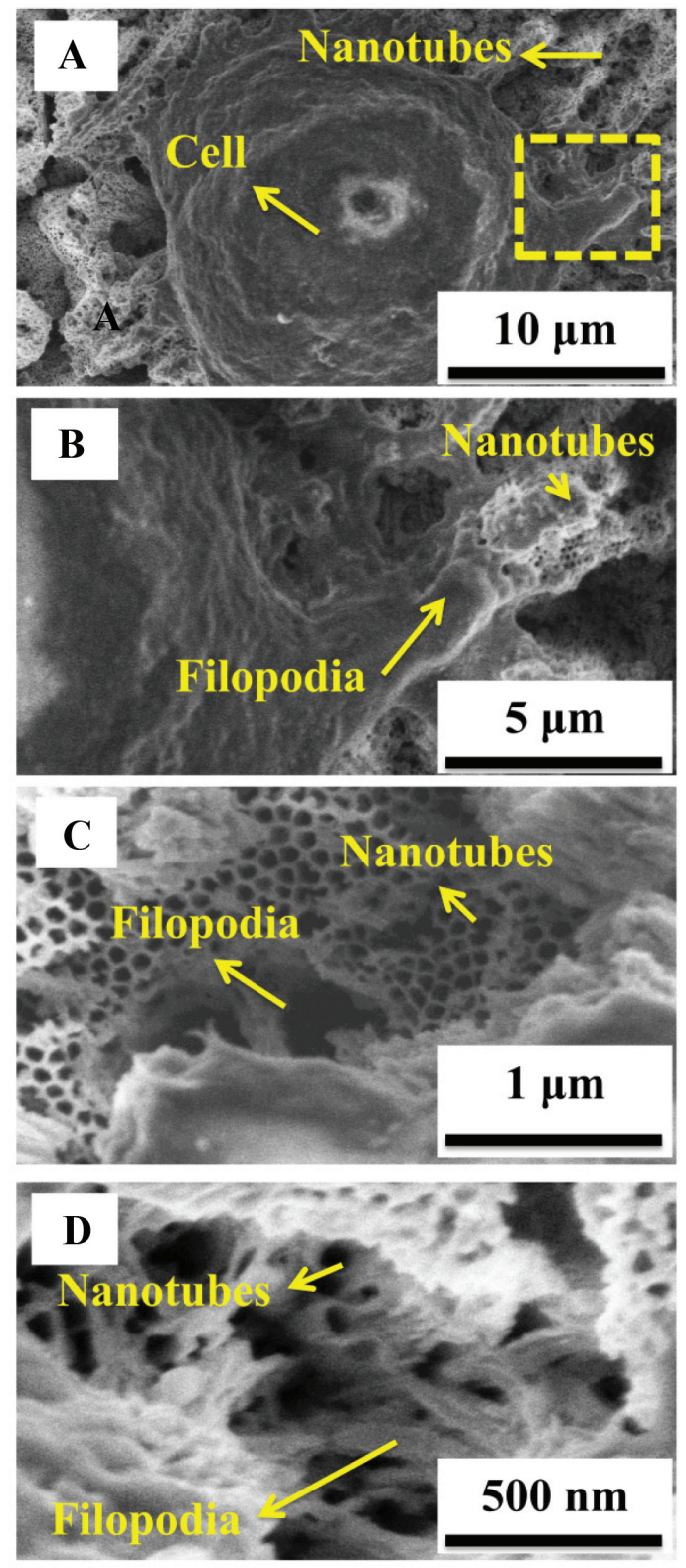

$\mathbf{E}$

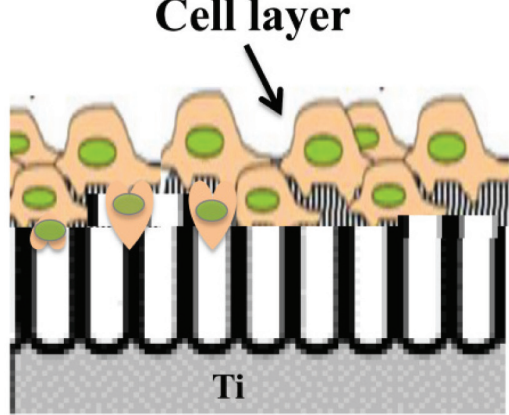

\section{cp-crystalline $\mathrm{TiO}_{2}$ nanotubes}
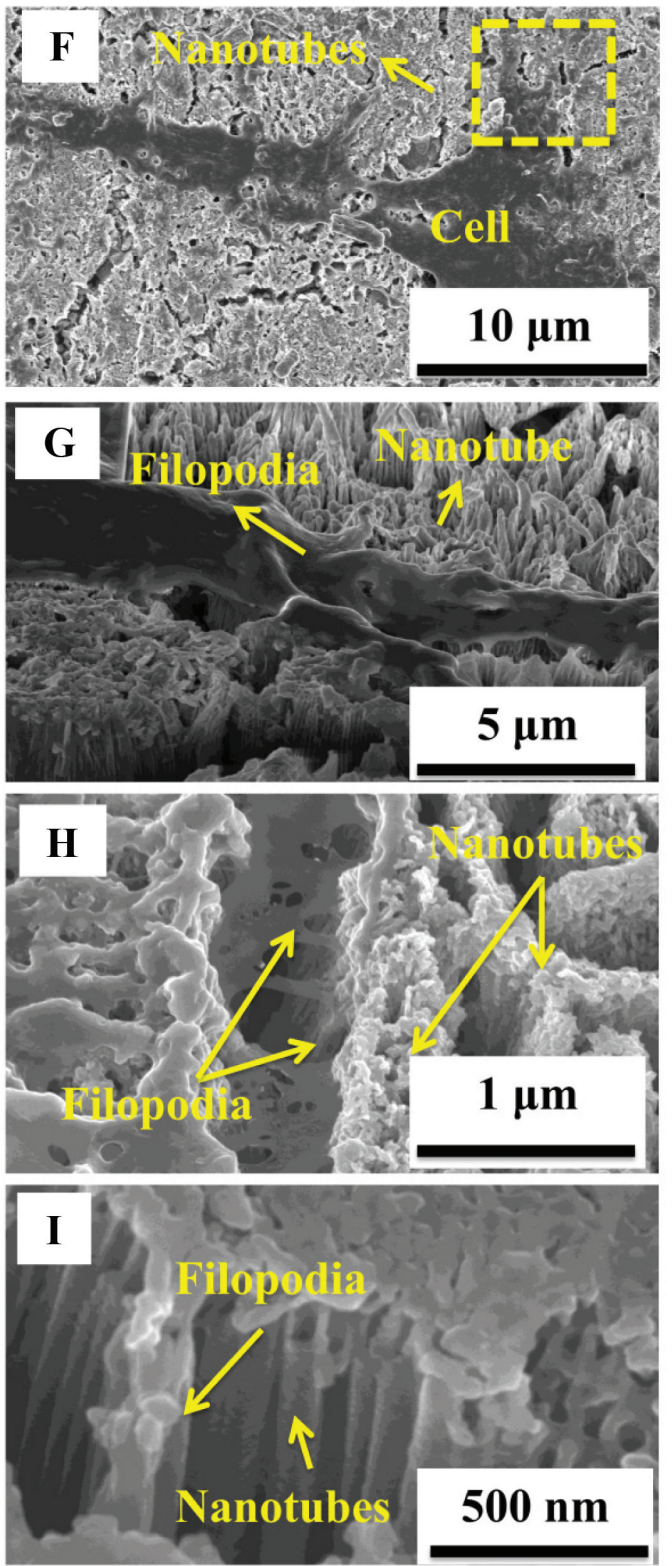

$\mathbf{J}$

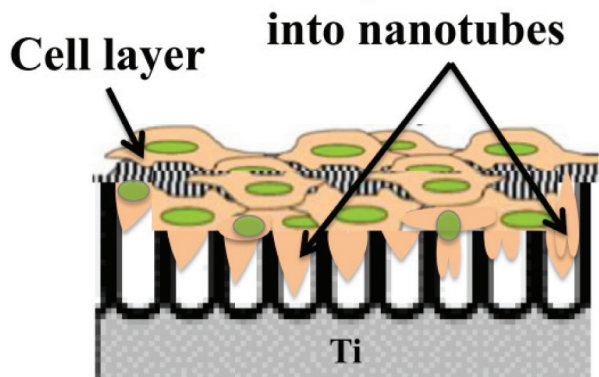

Figure 4 Scanning electron microscopy (SEM) images of osteoblast cells on $\mathrm{TiO}_{2}$ nanotubes grown on cP-Ti surface with (A-E) amorphous and (F-J) crystalline structure. The filopodia extension and anchorage to the nanotubes is compared in this figure. (A) Shows a single cell and (B) higher magnification view of dotted box in (A) where the cell filopodia can be observed. The images in $\mathbf{C}$ and $\mathbf{D}$ show that the cell filopodia has not extended or penetrated into the amorphous nanotubes. (E) The schematic shows the lack of cell filopodia penetration into the amorphous nanotubes. (F) Shows a single cell on crystalline nanotubes and (G) a higher magnification view of the dotted box in $(\mathbf{F})$. The images in $(\mathbf{H}$ and $\mathbf{I})$ show that the cell filopodia is quite extended and has penetrated into the crystalline nanotubes. $(\mathbf{J})$ The schematic shows the cell filopodia penetration into the amorphous nanotubes. 
In order to investigate the growth of filopodia within the hollow section of the amorphous and crystalline nanotubes, FIB technique was used (Figure 5). Low energy beam of Ga ions was used to carefully cut through sections of cells and reveal the extent of interaction with the underlying nanotube surface. Figure 5A shows an FIB milled osteoblast cell that is attached to cp-amorphous $\mathrm{TiO}_{2}$ nanotubes. Closer examination demonstrates that the nanotubes have kept their morphology intact under the cells (Figure 5B), while filopodia has not grown into the hollow section of the nanotubes (Figure 5C). However, the free end of cp-crystalline nanotubes is clogged (Figures 5D and $\mathrm{E}$ ) and the cell filopodia has grown into the nanotubes (Figure 5F).

Figure 6 shows SEM images of the FIB milled cells revealing that even after removal of the cell top section by FIB the nanotubes remain clogged (Figures 6A and B). The EDS chemical analysis showed that the bond between the nanotubes and the adjacent osteoblast cell layer is composed of $\mathrm{Ca}$ and $\mathrm{P}$ elements (Figure 6C), which appears to mimic the bond in the bone tissue itself. Figures 5 and 6 indicate that on the substrate surface, cell filopodia and the ECM remained attached following separation from the milled top section of the cell. These observations reveal a very close interfacial contact or direct contact between the osteoblasts and the nanotubes followed by $\mathrm{Ca}$ and $\mathrm{P}$ elements' deposition on the nanotubes (Figure 6C). These elements are the primary components of bone matrix and their deposition onto nanotubes, which is an indication that nanotubes have maintained osteoblast functionality. The proposed morphological structure of deposited $\mathrm{Ca}$ and $\mathrm{P}$ elements under SEM imaging is in agreement with the conclusions made by Das et al. ${ }^{41}$ The low intensity of the peaks is due to the fact that the EDS data were taken after only 3 days of culture. In addition, it should be noted that the $\mathrm{Ca}$ and $\mathrm{P}$ elemental peaks do not originate from the media. The concentration of $\mathrm{Ca}$ and $\mathrm{P}$ elements in the media is much lower than other inorganic components (Table 1). However, the EDS analysis does not indicate any peaks regarding other elements such as potassium $(\mathrm{K})$ and sodium $(\mathrm{Na})$. Moreover, the samples were washed several times to eliminate any entrapped media in nanotubes before EDS analysis. Therefore, the only reason for the presence of $\mathrm{Ca}$ and $\mathrm{P}$ elemental peaks is stimulation of cells by nanotube.

\section{Discussion}

FE-SEM images (Figure 1) confirm formation of nanotubes on both cp-Ti and alloy-Ti. The nanotubes have an average diameter of $100 \mathrm{~nm}$ and an average length of $1 \mu \mathrm{m}$. In agreement with the reports from Macak et $\mathrm{al}^{21}$ only the $\mathrm{Al}$ rich $\alpha$ phase of Ti alloy showed stable porous structures. The $\mathrm{V}$ rich $\beta$ phases etch faster and dissolve, leaving behind dark areas indicated by arrows in Figure 1F. Irrespective of the compositional elements in the substrate, the grown nanotubes are uniform and homogeneous.

TEM and XRD results (Figure 2) show that right after anodization, as-anodized nanotubes have an amorphous structure which transforms into an anatase phase during annealing.

FE-SEM images of osteoblasts incubated over surfaces demonstrate that the presence of nanotubes on cp-Ti substrate has been effective in increasing the number of attached cells (compare Figure 3A with B). Comparison between Figures $3 \mathrm{~B}$ and $\mathrm{C}$ shows a considerable increase in cell density and spreading for crystalline nanotubes. A similar observation can be made for the cells grown on an alloy-Ti surface (Figure 3D-F) however the density of cells is much lower on alloy-Ti.

Figure $3 \mathrm{G}$ shows the cell density increases as a function of incubation time. Also, the cell density is always higher on cp-Ti surfaces. The highest cell density $\left(\sim 2,500 / \mathrm{mm}^{2}\right)$ was obtained after 72 hours incubation of crystalline nanotubes grown on a cp-Ti surface which is $\sim 60 \%$ higher than amorphous nanotubes grown on cp-Ti. The cell density after 72 hours of incubation on crystalline nanotubes grown on cp-Ti is about $20 \%$ higher than similar nanotubes that were grown on alloy-Ti. Although the difference is not statistically significant, this observation is also consistent for the cells incubated for 24 and 48 hours suggesting that the chemistry of nanotubes can have an effect on cell density. The reduction in cell density on alloy-Ti surfaces may be due to slightly lower biocompatibility of the alloying elements ( $\mathrm{Al}$ and $\mathrm{V}$ ) and their oxides. ${ }^{42,43}$ In addition, the difference in cell density between the amorphous and crystalline nanotubes can be explained by hydrophilicity of the nanotubes as discussed in the next section.

Droplet contact angle is highly affected by surface treatments. ${ }^{44}$ After the anodization process, the droplet contact angles decreased in the range of 55\% 70\% compared to the bare substrate. This indicates that the creation of nanotube structures makes the surface more hydrophilic. Remarkably, the crystalline nanotubes had the most hydrophilic properties among all the other substrates. On the crystalline nanotube substrates, water droplet contact angles decreased $40 \% \sim 56 \%$ compared to the amorphous nanotube substrates.

In general, annealing metal generates a hydrophobic surface. ${ }^{45}$ Conversely, more hydrophilic surfaces were 

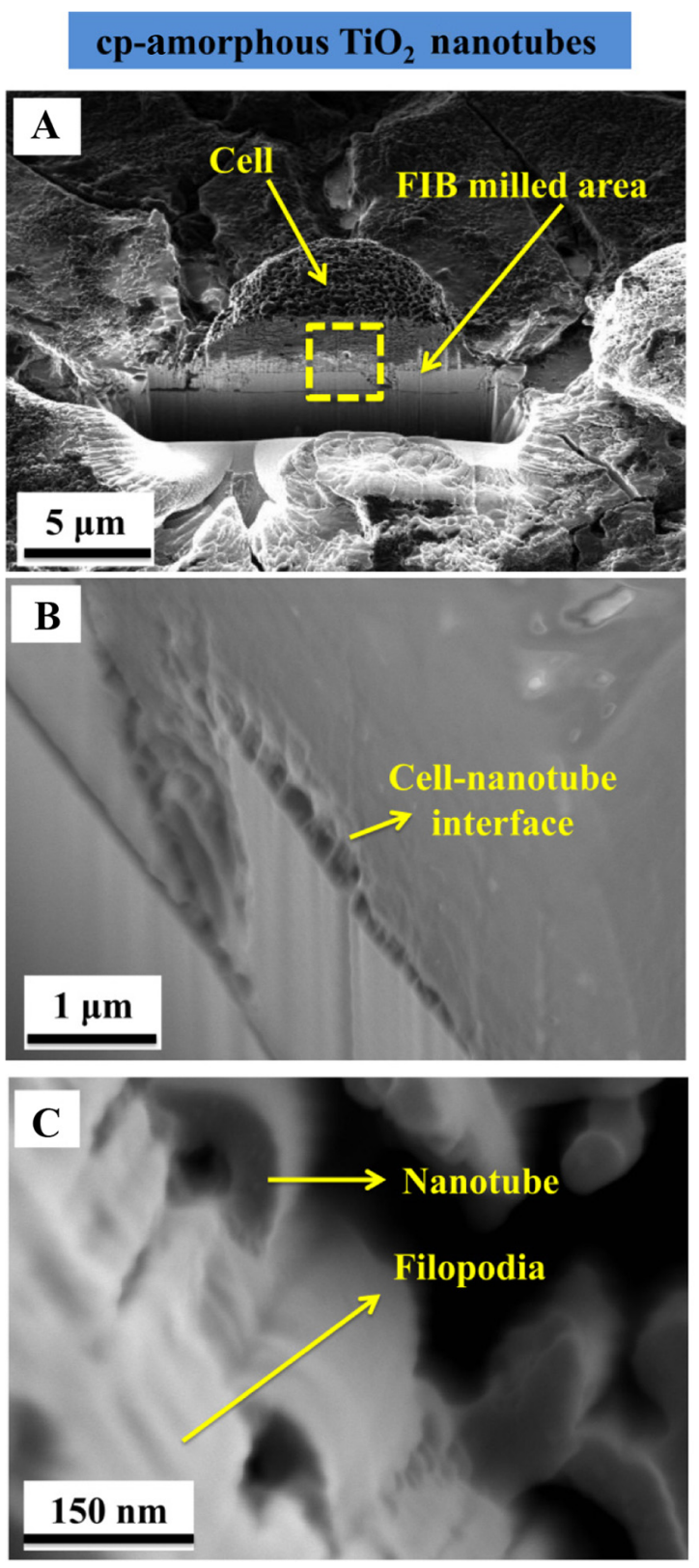

cp-crystalline $\mathrm{TiO}_{2}$ nanotubes
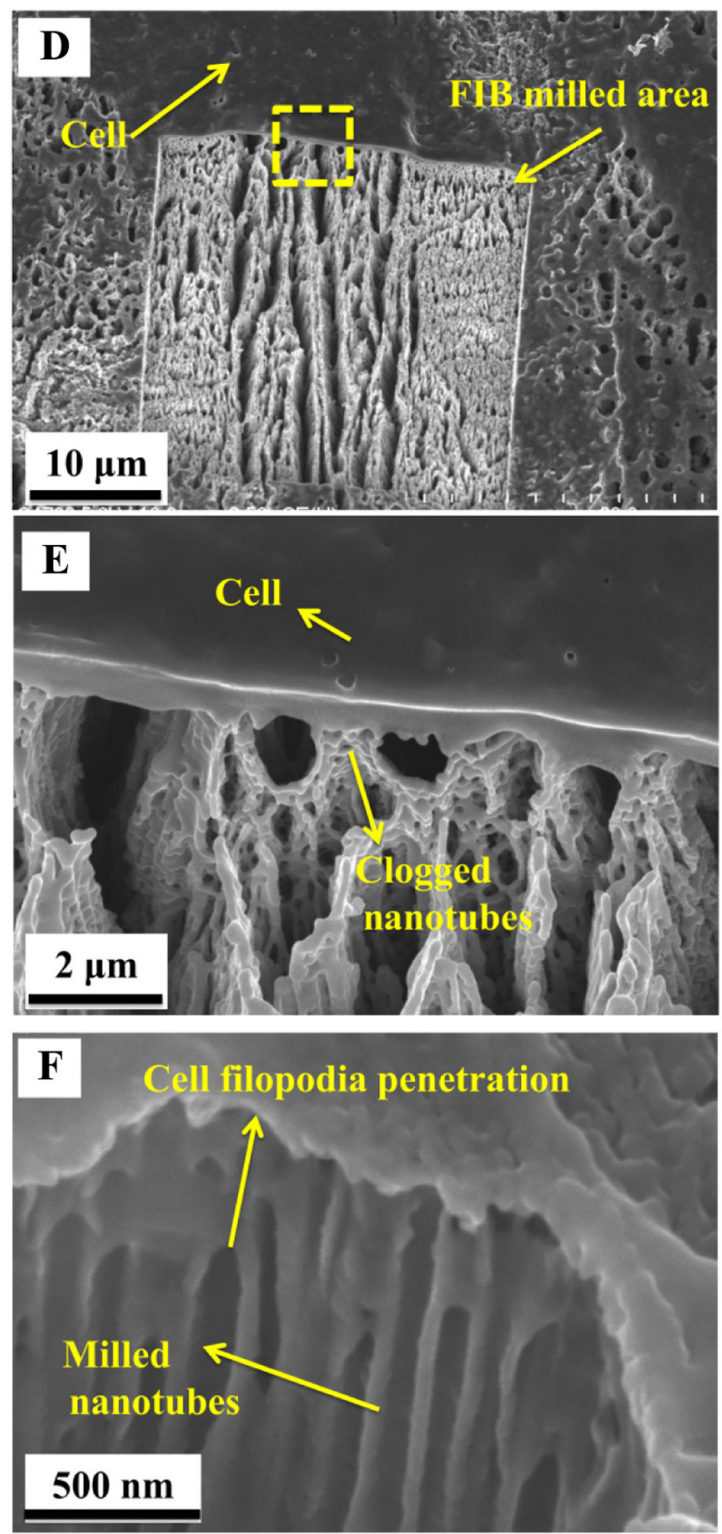

Figure 5 (A-C) The scanning electron microscopy (SEM) images show the focused ion beam (FIB) milled cross section of osteoblast cells cultured on the surface of cPamorphous $\mathrm{TiO}_{2}$ nanotubes. (B) Shows a zoomed-in view of the cell-nanotube interface marked by the dotted box in (A). (C) The filopodia is attached to the nanotube but has not penetrated inside the nanotubes (no clogging). (D-F) The FIB milled cross section of osteoblast cells cultured on the surface of cp-crystalline TiO ${ }_{2}$ nanotubes. (E) The image shows a zoomed-in view of the cell-nanotube interface marked by the dotted box in (D). (F) The image shows that the filopodia is attached to the nanotubes and penetrated inside the nanotubes (nanotube clogging).

produced by annealing in this study which results in higher cell density. In view of nanotube structure, the crystalline nanotubes are more effective in enhancing cell growth compared with amorphous nanotubes probably due to increased hydrophilicity. The rationale behind such a conclusion is that nanotube surfaces enhance surface energy as well as hydrophilicity of the surface due to the presence of functional hydroxyl groups on the surface. ${ }^{44}$ Considering that proteins are better absorbed on the hydrophilic $\mathrm{TiO}_{2}$ nanotube surfaces, cell adhesion is enhanced. This hypothesis is in agreement with
Yao et al's study ${ }^{46}$ which reported that the initial adsorption of proteins on anodized nanotube Ti was increased compared to anodized nanoparticles and un-anodized $\mathrm{Ti}$.

The importance of the interaction between osteoblast filopodia and $\mathrm{TiO}_{2}$ nanotubes has been the subject of several investigations. ${ }^{28,35,41}$ Popat et $\mathrm{al}^{28}$ investigated the effect of Ti nanotubes with different crystallographic structures on MC3T3-E1 osteoblast cells. They postulated that the cell filopodia grew inside the nanotubes, making a strong interlock between the cell and substrate. However, their 

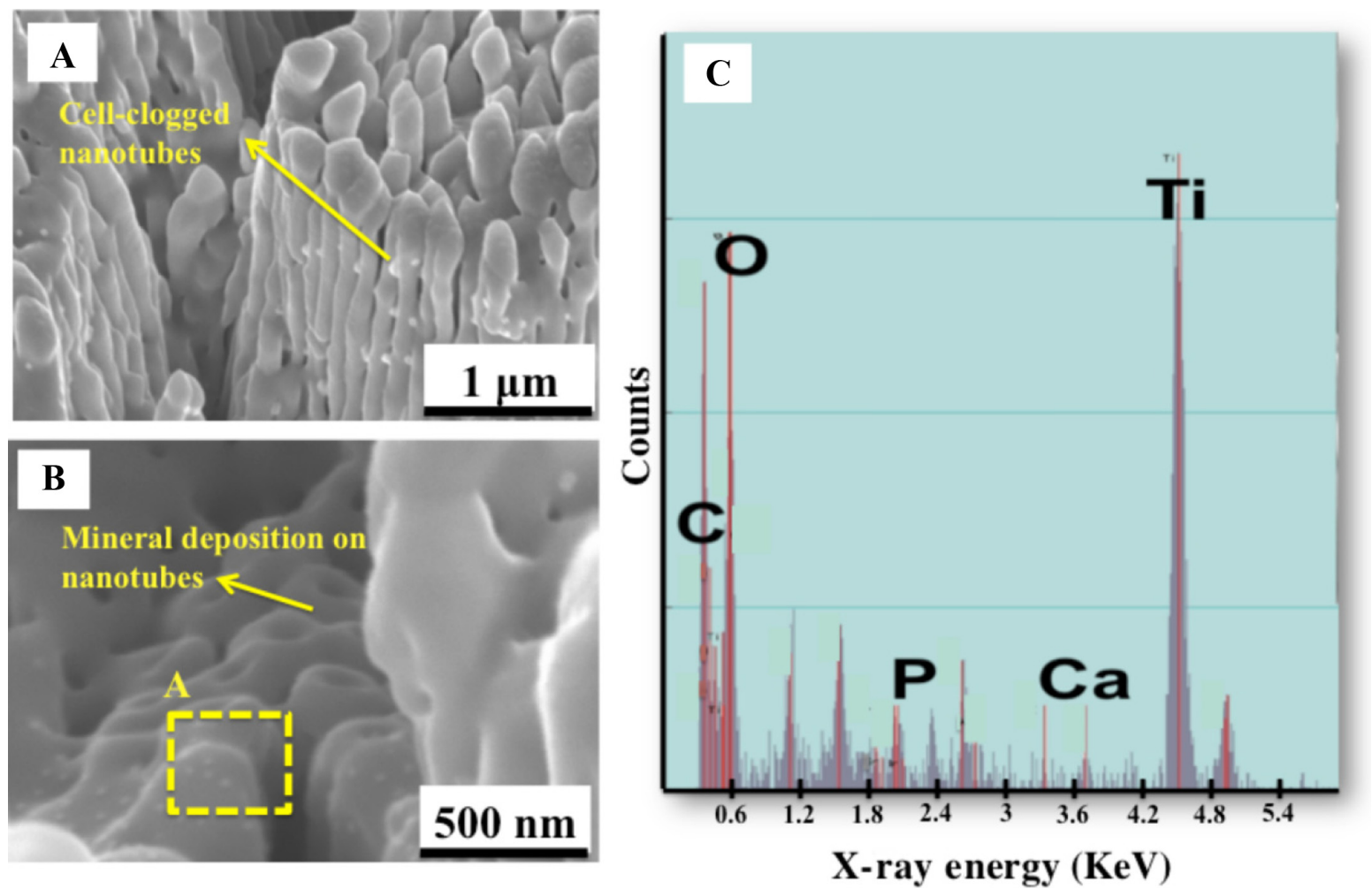

Figure 6 (A, B) The scanning electron microscopy (SEM) images show close views of the cp-crystalline TiO, nanotubes clogged by mineral deposition from cells. (C) Energy dispersive spectroscopy (EDS) signal from the area marked as A in (B) from an area with clogged nanotubes. The deposited minerals are composed of Ca and P, which are the primary components of bone matrix.

discussion on interlocked interactions between the nanotubes and cell filopodia is not conclusive enough due to lack of any structural evidence. Here, we have provided evidence of such an interlocked mechanism by means of SEM and FIB analysis. It is reasonable to conclude that the existence of atomic ordering in nanotubes and the resulting hydrophilicity would be essential to increase cell filopodia growth inside the nanotubes (Figure 4). The investigation of cell filopodia interaction with nanotubes by means of SEM has also been implemented by others. For instance, Popat et $\mathrm{al}^{28}$ also reported the filopodia extension on the nanotubes based on high magnification SEM image after 7 days of culture on a nanotubular surface. They discussed that their SEM results

Table I Concentration of inorganic salts in the media

\begin{tabular}{lll}
\hline Inorganic salts & $\begin{array}{l}\text { Concentration } \\
(\mathbf{m g} / \mathbf{L})\end{array}$ & $\mathbf{m M}$ \\
\hline $\begin{array}{l}\text { Calcium Chloride }\left(\mathrm{CaCl}_{2}\right) \\
\text { (anhyd.) }\end{array}$ & 200 & 1.8 \\
$\begin{array}{l}\text { Magnesium Sulfate }\left(\mathrm{MgSO}_{4}\right) \\
\text { (anhyd.) }\end{array}$ & 97.67 & 0.814 \\
$\begin{array}{l}\text { Potassium Chloride }(\mathrm{KCl}) \\
\text { Sodium Chloride }(\mathrm{NaCl})\end{array}$ & 400 & \\
$\begin{array}{l}\text { Sodium Phosphate monobasic } \\
\left(\mathrm{NaH}_{2} \mathrm{PO}_{4}-\mathrm{H}_{2} \mathrm{O}\right)\end{array}$ & 6,800 & 5.33 \\
\hline
\end{tabular}

Abbreviation: anhyd., anhydrous. show that cell extensions are protruding into the nanotubular architecture. In addition, Das et $\mathrm{al}^{41}$ have also investigated the cell-nanotube interaction by means of SEM to clarify the evidence of filopodia anchorage to nanotubes. Based on this SEM evidence, they reported that filopodia from human osteoblast cells use the nanoporous $\mathrm{TiO}_{2}$ surface as anchorage sites for attachment.

In addition, as can be seen from Figure 5, the FIB results revealed that the cells sustained very high vacuum without visible damage and they physically survived ion beam milling and imaging. Moreover, ion milling revealed many internal features of cells at the submicron scale as well as the high interaction and growth of the cells among the nanotubes. This showed that FIB and SEM could be applied on dried biological material that is not prepared following standard cryopreservation methods, glutaraldehyde or a combination of glutaraldehyde and formaldehyde procedures. ${ }^{47}$

EDS analysis results (Figure 6) are in agreement with previous studies. Popat et $\mathrm{a}^{28}$ also reported deposition of $\mathrm{Ca}$ and $\mathrm{P}$ as the indication of bone matrix formation. Yao et $\mathrm{al}^{13}$ also observed more Ca deposition by osteoblasts on anodized nanotube-like Ti compared with un-anodized Ti.

The results of the current investigation indicate the formation of ECM on the nanotubes initiated by deposition of 
$\mathrm{Ca}$ and $\mathrm{P} .{ }^{28}$ This production of ECM is the result of osteoblast migration and healthy cellular activity in both crystalline and amorphous nanotubular surfaces. In fact, it is possible to consider the nanotubes as anchors for the cell filopodia to "grab" onto and have a facilitated migration along the surface. This anchorage benefit of nanotubes together with the strong hydrophilic properties in crystalline nanotubes appear to have increased osteoblast density in annealed nanotubes and higher interactions with them. Therefore, the observations made in the present investigation can be promising for the development of implants with high-cohesion osseointegration.

\section{Conclusion}

The osteoblast cell culture experiments indicated that the presence of nanotube morphology increased the total cell density and spreading. This increase was correlated with the anchoring effect of nanotubes for the cell filopodia to "grab" onto, facilitating migration along the surface. The early deposition of $\mathrm{Ca}$ and $\mathrm{P}$ onto nanotubes indicates that nanotubes have maintained osteoblast functionality.

It was observed that the chemical composition of the substrate strongly affected the cell density. In particular, the total cell density of nanotubes grown on a cp-Ti surface was higher in comparison to the cell density of nanotubes grown on an alloy-Ti surface. This behavior can be explained by slightly lower biocompatibility of the alloying elements (Al and $\mathrm{V}$ in this case) and their oxides.

Interestingly, the high surface wettability due to crystallinity is highly influential on further cell spreading and extension of the cell filopodia into the hollow space of nanotubes. In particular, the cell's filopodia extended into the crystalline nanotubes while much less penetration was observed for the cells grown on amorphous nanotubes. This was explained by the super hydrophilicity of crystalline nanotubes' surfaces in comparison to amorphous nanotubes.

The anchorage benefit of nanotubes together with their strong hydrophilic properties appear to cause increased osteoblast density in annealed nanotubular surfaces in comparison with anodized ones. This research can enable the determination of an optimal implant surface modification where implant-bone interlock and bone-cell density is highest.

\section{Acknowledgments}

The authors thank Mr Owen Mills and the Applied Chemical and Morphological Analysis Laboratory at Michigan Technological University for providing microscopy support to conduct this research. We would also like to thank Dr William Hendrickson, director of Research Resource
Center at UIC for providing laboratory space to carry out some of the analysis related to the in vitro experiments.

\section{Disclosure}

The authors have no conflicts of interest to report.

\section{References}

1. Massia SP. Cell-extracellular matrix interactions relevant to vascular tissue engineering. In: Landes Bioscience. Tissue Engineering of Vascular Prosthetic Grafts. 1999.

2. Webster TJ, Ergun C, Doremus RH, Siegel RW, Bizios R. Specific proteins mediate enhanced osteoblast adhesion on nanophase ceramics. J Biomed Mater Res. 2000;51(3):475-483.

3. Schneider G, Burridge K. Formation of focal adhesions by osteoblasts adhering to different substrata. Exp Cell Res. 1994;214(1):264-269.

4. Steele JG, Dalton BA, Johnson G, Underwood PA. Polystyrene chemistry affects vitronectin activity - an explanation for cell attachment to tissue-culture polystyrene but not to unmodified polystyrene. J Biomed Mater Res. 1993;27(7):927-940.

5. Dalton BA, McFarland CD, Gengenbach TR, Griesser HJ, Steele JG. Polymer surface chemistry and bone cell migration. J Biomater $S c i$ Polym Ed. 1998;9(8):781-799.

6. Webb K, Hlady V, Tresco PA. Relationships among cell attachment, spreading, cytoskeletal organization, and migration rate for anchoragedependent cells on model surfaces. J Biomed Mater Res. 2000;49(3): 362-368.

7. Takebe J, Itoh S, Okada J, Ishibashi K. Anodic oxidation and hydrothermal treatment of titanium results in a surface that causes increased attachment and altered cytoskeletal morphology of rat bone marrow stromal cells in vitro. J Biomed Mater Res. 2000;51(3):398-407.

8. Liao HH, Andersson AS, Sutherland D, Petronis S, Kasemo B, Thomsen P. Response of rat osteoblast-like cells to microstructured model surfaces in vitro. Biomaterials. 2003;24(4):649-654.

9. Doroudian G, Curtis MW, Gang A, Russell B. Cyclic strain dominates over microtopography in regulating cytoskeletal and focal adhesion remodeling of human mesenchymal stem cells. Biochem Biophys Res Commun. 2013;430(3):1040-1046.

10. Rabiee SM, Mortazavi SM, Moztarzadeh F, et al. Association of a synthetic bone graft and bone marrow cells as a composite biomaterial. Biotechnology and Bioprocess Engineering. 2009;14(1):1-5.

11. Yu WQ, Zhang YL, Jiang XQ, Zhang FQ. In vitro behavior of MC3T3-E1 preosteoblast with different annealing temperature titania nanotubes. Oral Dis. 2010;16(7):624-630.

12. von der Mark K, Park J, Bauer S, Schmuki P. Nanoscale engineering of biomimetic surfaces: cues from the extracellular matrix. Cell Tissue Res. 2010;339(1):131-153.

13. Yao C, Slamovich EB, Webster TJ. Enhanced osteoblast functions on anodized titanium with nanotube-like structures. J Biomed Mater Res A. 2008;85A(1):157-166.

14. Sun L, Berndt CC, Gross KA, Kucuk A. Material fundamentals and clinical performance of plasma-sprayed hydroxyapatite coatings: a review. J Biomed Mater Res. 2001;58(5):570-592.

15. Tami AE, Schaffler MB, Knothe Tate ML. Probing the tissue to subcellular level structure underlying bone's molecular sieving function. Biorheology. 2003;40(6):577-590.

16. Nourmohammadzadeh M, Lo JF, Bochenek M, et al. Microfluidic Array with Integrated Oxygenation Control for Real-Time Live-Cell Imaging: Effect of Hypoxia on Physiology of Microencapsulated Pancreatic Islets. Anal Chem. 2013;85(23):11240-11249.

17. Brammer $\mathrm{KS}, \mathrm{Oh} \mathrm{S}, \mathrm{Cobb} \mathrm{CJ}$, et al. Improved bone-forming functionality on diameter-controlled $\mathrm{TiO}_{2}$ nanotube surface. Acta Biomater. 2009; 5(8):3215-3223.

18. Roy P, Berger S, Schmuki P. TiO ${ }_{2}$ Nanotubes: Synthesis and Applications. Angew Chem Int Ed Engl. 2011;50(13):2904-2939. 
19. Ghicov A, Schmuki P. Self-ordering electrochemistry: a review on growth and functionality of $\mathrm{TiO}_{2}$ nanotubes and other self-aligned $\mathrm{MOx}$ structures. Chem Commun (Camb). 2009;(20):2791-2808.

20. Park J, Bauer S, Schmuki P, von der Mark K. Narrow Window in Nanoscale Dependent Activation of Endothelial Cell Growth and Differentiation on $\mathrm{TiO}_{2}$ Nanotube Surfaces. Nano Lett. 2009;9(9):3157-3164.

21. Macak JM, Tsuchiya H, Taveira L, Ghicov A, Schmuki P. Selforganized nanotubular oxide layers on Ti-6A1-7Nb and Ti-6A1-4V formed by anodization in $\mathrm{NH}_{4} \mathrm{~F}$ solutions. J Biomed Mater Res A. 2005; 75A(4):928-933.

22. Bauer S, Park J, von der Mark, Schmuki P. Improved attachment of mesenchymal stem cells on super-hydrophobic $\mathrm{TiO}_{2}$ nanotubes. Acta Biomater. 2008;4(5):1576-1582.

23. Hamlekhan A, Butt A, Patel S, et al. Fabrication of Anti-Aging $\mathrm{TiO}_{2}$ Nanotubes on Biomedical Ti Alloys. PLoS One. 2014;9(5):1-10.

24. Patel SB, Hamlekhan A, Royhman D, et al. Enhancing Surface Characteristics of Ti-6Al-4V for Bio-implants Using Integrated Anodization and Thermal Oxidation. J Mater Chem B. 2014;2(23):3597-3608.

25. Tan AW, Pingguan-Murphy B, Ahmad R, Akbar SA. Review of titania nanotubes: Fabrication and cellular response. Ceramics International. 2012;38(6):4421-4435.

26. Butt A, Hamlekhan A, Patel SB, et al. A Novel Investigation of the Formation of $\mathrm{TiO}_{2}$ Nanotubes on Thermally Formed Oxide of Ti6Al-4V. J Oral Implantol. Epub 2014 March 15.

27. Azhang Hamlekhan, AB, Sweetu Patel, et al. Optimization of Anodization and Annealing Condition Enhances $\mathrm{TiO}_{2}$ Nanotubular Surface Hydrophilicity. TMS 2014 Supplemental Proceedings. John Wiley \& Sons, Inc, 2014.

28. Popat KC, Leoni L, Grimes CA, Desai TA. Influence of engineered titania nanotubular surfaces on bone cells. Biomaterials. 2007;28(21): 3188-3197.

29. Bjursten LM, Rasmusson L, Oh S, Smith GC, Brammer KS, Jin S. Titanium dioxide nanotubes enhance bone bonding in vivo. $J$ Biomed Mater Res A. 2010;92A(3):1218-1224.

30. Hazan R, Sreekantan S, Khalil AA, Nordin IM, Mat I. Surface Engineering of titania for Excellent Fibroblast 3T3 Cell-Metal Interaction. Journal of Physical Science. 2009;20(1):35-47.

31. Gongadze E, Kabaso D, Bauer S, Park J, Schmuki P, Iglic A. Adhesion of Osteoblasts to a Vertically Aligned $\mathrm{TiO}_{2}$ Nanotube Surface. Mini Rev Med Chem. 2013;13(2):194-200.

32. Bauer S, Park J, Faltenbacher J, et al. Size selective behavior of mesenchymal stem cells on $\mathrm{ZrO}_{2}$ and $\mathrm{TiO}_{2}$ nanotube arrays. Integr Biol (Camb). 2009;1(8-9):525-532.
33. Chen CS. Mechanotransduction - a field pulling together? J Cell Sci. 2008;121(20):3285-3292.

34. Park J, Bauer S, von der Mark K, Schmuki P. Nanosize and vitality: $\mathrm{TiO}_{2}$ nanotube diameter directs cell fate. Nano Lett. 2007;7(6):1686-1691.

35. Oh S, Daraio C, Chen LH, Pisanic TR, Finones RR, Jin S. Significantly accelerated osteoblast cell growth on aligned $\mathrm{TiO}_{2}$ nanotubes. J Biomed Mater Res A. 2006;78A(1):97-103.

36. Oh S, Brammer KS, Li YS, Teng D, Engler AJ, Chien S, Jin S. Stem cell fate dictated solely by altered nanotube dimension. Proc Natl Acad Sci U S A. 2009;106(7):2130-2135.

37. Wang D, Christensen K, Chawla K, Xiao G, Krebsbach PH, Franceschi RT. Isolation and characterization of MC3T3-E1 preosteoblast subclones with distinct in vitro and in vivo differentiation mineralization potential. J Bone Miner Res. 1999;14(6):893-903.

38. Luckey HA, Kubli F. Titanium alloys in surgical implants. Phoenix, Ariz: ASTM International, 1983

39. Brunette DM, Tengvall P, Textor M, Thomsen P. Titanium in medicine. New York: Springer, 2001

40. Lee J, Hurson S, Tadros H, Schupbach P, Susin C, Wikesjo UM. Crestal remodelling and osseointegration at surface-modified commercially pure titanium and titanium alloy implants in a canine model. $J$ Clin Periodontol. 2012;39(8):781-788.

41. Das $\mathrm{K}$, Bose $\mathrm{S}$, Bandyopadhyay $\mathrm{A}$. $\mathrm{TiO}_{2}$ nanotubes on Ti: Influence of nanoscale morphology on bone cell-materials interaction. J Biomed Mater Res A. 2009;90A(1):225-237.

42. Eisenbarth E, Velten D, Muller M, Thull R, Breme J. Biocompatibility of beta-stabilizing elements of titanium alloys. Biomaterials. 2004; 25(26):5705-5713.

43. Wapner KL. Implications of metallic corrosion in total knee arthroplasty. Clin Orthop Relat Res. 1991;(271):12-20.

44. Shin DH, Shokuhfar T, Choi CK, Lee SH, Friedrich C. Wettability changes of $\mathrm{TiO}_{2}$ nanotube surfaces. Nanotechnology. 2011; 22(31):1-7.

45. Shinde VR, Lokhande CD, Mane RS, Han SH. Hydrophobic and textured $\mathrm{ZnO}$ films deposited by chemical bath deposition: annealing effect. Applied Surface Science. 2005;245(1-4):407-413.

46. Yao C, Perla V, McKenzie JL, Slamovich EB, Webster TJ. Anodized Ti and Ti(6)Al(4)V Possessing Nanometer Surface Features Enhances Osteoblast Adhesion. Journal of Biomedical Nanotechnology. 2005; 1(1):68-73.

47. Leser V, Drobne D, Pipan Z, Milani M, Tatti F. Comparison of different preparation methods of biological samples for FIB milling and SEM investigation. J Microsc. 2009;233(2):309-319.
International Journal of Nanomedicine

\section{Publish your work in this journal}

The International Journal of Nanomedicine is an international, peerreviewed journal focusing on the application of nanotechnology in diagnostics, therapeutics, and drug delivery systems throughout the biomedical field. This journal is indexed on PubMed Central, MedLine, CAS, SciSearch ${ }^{\circledR}$, Current Contents ${ }^{\circledR} /$ Clinical Medicine,

\section{Dovepress}

Journal Citation Reports/Science Edition, EMBase, Scopus and the Elsevier Bibliographic databases. The manuscript management system is completely online and includes a very quick and fair peer-review system, which is all easy to use. Visit http://www.dovepress.com/ testimonials.php to read real quotes from published authors. 